УДК 355.40

Олексіюк Вадим Вімалійович

Військова частина А1906, Київ, Україна

\title{
МЕТОДИКА ВИЗНАЧЕННЯ СТРУКТУРИ ОРГАНУ УПРАВЛІННЯ РОЗВІДКОЮ
}

\begin{abstract}
У статті запропоновано методику обтрунтування раціональної структури органів управління розвідкою на основі методу кластерного аналізу, метою якого є пошук наявних структур, щзо виражається в утворенні груп схожих між собою об'єктів - кластерів. Вибір стратегї кластеризації полягає у визначенні правил об'єднання об'єктів у кластери. Дані до кластерного аналізу підготовлюються шляхом формування матриці співвідношень. На відміну від інших методів, ией метод дає змогу класифікувати об'єкти не за однією, а за декількома ознаками одночасно, як сукупність взаємопов'язаних функиіональних підсистем з визначенням функиій кожної з них. Наведено варіант дендрограми об'єднання кластерів (структурних підрозділів) за виміром близькості функиій та завдань. Результати дослідження обтрунтовані практичними розрахунками $i$ можуть бути застосовані для удосконалення науково-методичного апарату визначення, оцінювання ефективності розроблених варіантів структури органу управління розвідки та вибору найбільш прийнятної альтернативи.
\end{abstract}

Ключові слова: орган управління розвідкою, структура, кластерний аналіз, Збройні Сили Украйни.

\section{Вступ}

Постановка проблеми.

Постійне реформування Міністерства оборони і Збройних Сил України, у тому числі органів управління розвідкою (ОУР) усіх рівнів, яке відбувалося переважно за рахунок скорочення (оптимізації) їх чисельності, призвело до дисбалансу між фактичними можливостями та функціями, які на них покладені. ОУР виявились нездатними в повному обсязі виконувати свої функції в умовах особливого періоду, а їх організаційно-штатна структура, як і структура органів розвідки оперативного і тактичного рівнів - здатною своєчасно i ефективно виконувати нетрадиційні і специфічні завдання (їх значний обсяг), які на них покладаються в умовах ведення гібридної війни.

Такий стан справ вимагає негайних кардинальних змін та глибокого реформування, а не подальшого удосконалення існуючої системи воєнної розвідки України. Постає гостра необхідність зміни підходу (підходів) до побудови комплекту розвідки ЗС України (у тому числі ОУР). Зазначені підходи повинні формуватись на основі принципів багатофункціональності, достатньої ефективності функціонування, збалансованості компонентів, оперативної мобільності, воєнно-економічної доцільності, сумісності систем управління компонентів (ОУР) та адекватності існуючій (прогнозованій) обстановці та умовам застосування.

Аналіз остатніх досліджень і публікацій. Проведений аналіз досліджень та публікацій [1-6] свідчить, що на цей час розроблені певні підходи до вирішення завдання визначення та обгрунтування організаційної структури органів військового управління, угруповань військ на основі побудови моделей функціонування складних систем військового призначення, якими $\epsilon$ органи військового управління всіх рівнів.

Зокрема, визначені специфічні особливості визначення раціонального складу складної системи військового призначення, якою є ОУР, а саме: неповнота й невизначеність вихідної інформації при функціонуванні системи в різних умовах обстановки; багатокритеріальність завдання, що пов'язано з необхідністю врахування великої кількості часткових показників; наявність кількісних i якісних показників, які необхідно враховувати; неможливість застосування класичних методів оптимізації [7].

Існуючі підходи визначають структуру ОУР без чіткого розбиття їх на складові: група, відділ, управління тощо, цілісного науково-методичного апарату визначення структури ОУР на цей час немає.

Тому розробка науково обгрунтованих підходів до визначення раціональної структури ОУР $\epsilon$ актуальним науково-практичним завданням.

Метою статті є: розробка методики визначення (обгрунтування) структури ОУР оперативного рівня.

\section{Виклад основного матеріалу дослідження.}

ОУР являє собою організовану сукупність фахівців, які виконують різні завдання за своїм змістом i напрямом. Для створення структури такого органу потрібно об'єднати виконавців завдань у групи, служби, відділи, управління за обраним показником. Таким показником може бути близькість робіт, які виконують ці фахівці. 
Для вирішення цього наукового завдання доцільно використати метод кластерного аналізу, метою якого $є$ пошук наявних структур, що виражається в утворенні груп схожих між собою об'єктів кластерів, для структурних підрозділів ОУР групи, служби, відділи, управління. На відміну від інших методів, цей метод дає змогу класифікувати об'єкти не за однією, а за декількома ознаками одночасно [4].

Використання методики визначення структури ОУР, що грунтується на використанні апарату кластерного аналізу, передбачає ряд обмежень та припущень:

завдання, що покладаються на ОУР, у межах певної підсистеми, мають бути одного рівня виконання;

масив даних до кластерного аналізу встановлюється шляхом проведення експертного оцінювання;

участь кожної групи у виконанні поставлених завдань оцінюється експертом у відсотковому відношенні так, щоб сума за всіма завданнями становила $100 \%$.

У загальному вигляд проведення кластерного аналізу передбачає кілька етапів: підготовка даних до кластерного аналізу; вибір міри відстані між об'єктами та іiі обчислення; вибір стратегії кластеризації; вибір методу кластерного аналізу; інтерпретація результатів кластеризації.

Дані до кластерного аналізу підготовлюються шляхом формування матриці співвідношень. Вихідна множина складається $3 m$ підрозділів, що виконують $k$ завдань, які покладаються на ОУР (табл.1).

Таблиця 1. Матриця співвідношень

\begin{tabular}{|c|c|c|c|c|}
\hline & $\begin{array}{c}\text { Завдання } \\
k_{l}\end{array}$ & $\begin{array}{c}\text { Завдання } \\
k_{2}\end{array}$ & $\begin{array}{c}\text { Завдання } \\
k_{i}\end{array}$ \\
\hline $\begin{array}{c}\text { Підрозділ } \\
m_{l}\end{array}$ & $m_{1} / k_{l}$ & $m_{l} / k_{2}$ & & $m_{1} / k_{i}$ \\
\hline $\begin{array}{c}\text { Підрозділ } \\
m_{2}\end{array}$ & $m_{2} / k_{l}$ & $m_{2} / k_{2}$ & & $m_{2} / k_{i}$ \\
\hline$\ldots$ & $\ldots$ & $\ldots$ & & $\ldots$ \\
\hline $\begin{array}{c}\text { Підрозділ } \\
m_{j}\end{array}$ & $m_{j} / k_{l}$ & $m_{j} / k_{2}$ & & $m_{j} k_{i}$ \\
\hline
\end{tabular}

При залученні для формування матриці співвідношень $X_{m k}$ групи $3 Y$ експертів числове значення судження визначається як середнє арифметичне окремих суджень експертів:

$$
\alpha_{x}=\frac{\sum_{b=1}^{Y} \mathrm{q}_{b} \alpha_{b}}{Y},
$$

де $\alpha_{x}-$ судження $b$-го експерта;

$q_{b}$ - вага $b$-го експерта.

Наступним кроком є вибір міри відстані між об'єктами та іiї обчислення. В кластерному аналізі існує декілька підходів до визначення міри відстаней: евклідова відстань, квадрат евклідової відстані, відстань Чебишева, відсоток невідповідності, 1-коефіцієнт кореляції Пірсона, манхетинівська відстань, метрика Мінковського, відстань Махаланобіса. Для кількісних шкал, якою $\epsilon$ матриця співвідношень груп виконавців до завдань, застосовується евклідова відстань.

Евклідова відстань між об'єктами являє собою геометричну відстань між ними у багатовимірному просторі i визначається за формулою:

$$
\begin{gathered}
l_{r c}=\sqrt{\sum_{i=1}^{k}\left(y_{r i}-y_{c i}\right)^{2}}, \\
\text { де значення } y_{r i}=\frac{\alpha_{x i}-\bar{\alpha} x}{S_{x}} ; y_{c i}=\frac{\alpha_{i x}-\bar{\alpha} x}{S_{x}} \\
\overline{\alpha_{x}}-\text { середне арифметичне значень } \alpha_{x} \text { за }
\end{gathered}
$$
завданнями;

$S_{x}$ - стандартне відхилення значень суджень експертів за завданнями;

$k$ - кількість завдань.

3 проведенням послідовних обчислень відстаней між усіма групами виконавців, будується матриця відстаней між ними:

$$
L=\left(\begin{array}{cccc}
0 & l_{12} & \cdots & l_{1 c} \\
l_{21} & 0 & \cdots & l_{2 c} \\
\vdots & \vdots & & \\
l_{r 1} & l_{r 2} & & 0
\end{array}\right)
$$

при $r=c l_{r c}=0, r, c=1,2, \ldots, m$. Чим менше значення $l_{r c}$, тим ближче знаходяться між собою групи виконання завдань.

Вибір стратегії кластеризації полягає у визначенні правил об'єднання об'єктів у кластери. Основними правилами кластеризації є [4]:

стратегія одиночного зв'язку. Стратегія ніби нанизує два кластери разом, i в результаті кластери подаються у вигляді довгих “ланцюжків";

стратегія повного зв'язку. Стратегія добре працює, коли кластери належать різним класам;

стратегія незваженого попарного середнього ефективна у випадку реального об'єднання об'єктів як у “кущі”, так і в “ланцюжки”, що дає змогу показати ієрархічне об’єднання об'єктів;

стратегія зваженого попарного середнього. Ця стратегія також дає змогу об'єднати об'єкти як у “кущі”, так і в “ланцюжки” і використовується тоді, коли передбачають появу кластерів нерівного розміру;

стратегія Варда. Вона вважається ефективною, але при їі використанні створюються кластери малого розміру. 
Для визначення структури ОУР доцільно обрати стратегію зваженого попарного середнього, яка дає змогу об'єднати групи виконавців 3 їх ієрархічним поданням і з визначенням їх розміру. Розрахунок проводиться за таким виразом:

$$
P\left(K_{s} K_{t}\right)=\frac{1}{n_{s} n_{t}} \sum_{L_{r}=1}^{K_{s}} \sum_{L_{c}=1}^{K_{t}} d\left(L_{r}, L_{c}\right),
$$

де $P\left(K_{s} K_{t}\right)$ - відстань між об'єктами (кластерами) $K_{s}$ i $K_{t}$;

$n_{s}, n_{t}-$ кількість елементів в кластерах $K_{s}$ i $K_{t}$ відповідно;

$L_{r}, L_{c} \quad$ - об'єкти (кластери), за якими відбувається пошук подібності;

\section{$d$ - відстань між $L_{r}$ та $L_{c}$.}

Для кінцевої інтерпретації отриманих даних доцільно обрати метод деревоподібної кластеризації, що забезпечує побудову ієрархічного кластерного дерева у вигляді дендрограми (рис. 1).

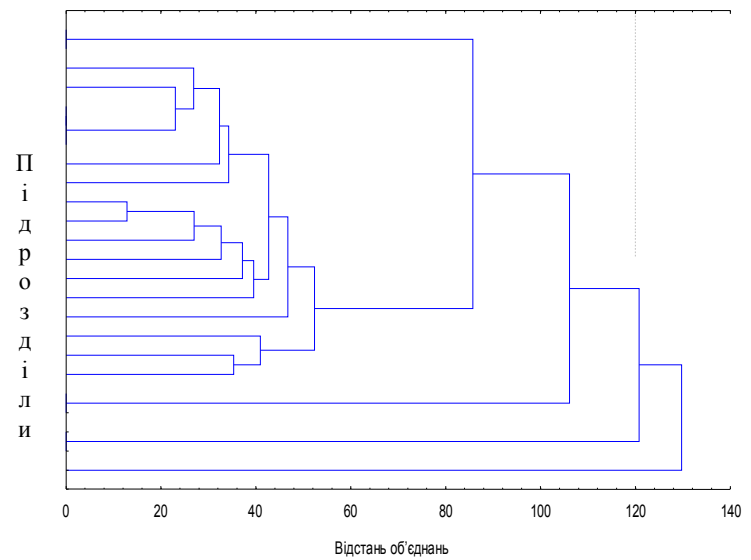

Рисунок 1. Приклад дендрограми об'єднання кластерів (варіант)

На кінцевому етапі здійснюється інтерпретація отриманих результатів. Інтерпретуючи кластерні дерева, слід намагатися в межах кожного 3 виділених кластерів знайти певний смисловий інваріант, який пояснює причину об'єднання об'єктів у цей кластер. Для цього додатково можна використати вихідний масив даних. У результаті такого аналізу необхідно знайти суть об'єднання кластерів у відповідні підсистеми ОУР.

На підставі наведеного, алгоритм методики визначення структури ОУР має вигляд, як показано на рис. 2 .

\section{Лimepamypa}

1. Косогов О.М. Методика визначення структури системи інформаційної безпеки Міністерства оборони України та Збройних Сил України / О.М.Косогов, А.О.Сірик // Зб. наук. праць. - Х.: Харківський національний університет Повітряних Сил імені Івана Кожедуба №3 (52), 2017, - С. 30-34.
Формування матриці груп виконавців та Р3, що стоять перед органом управління розвідки

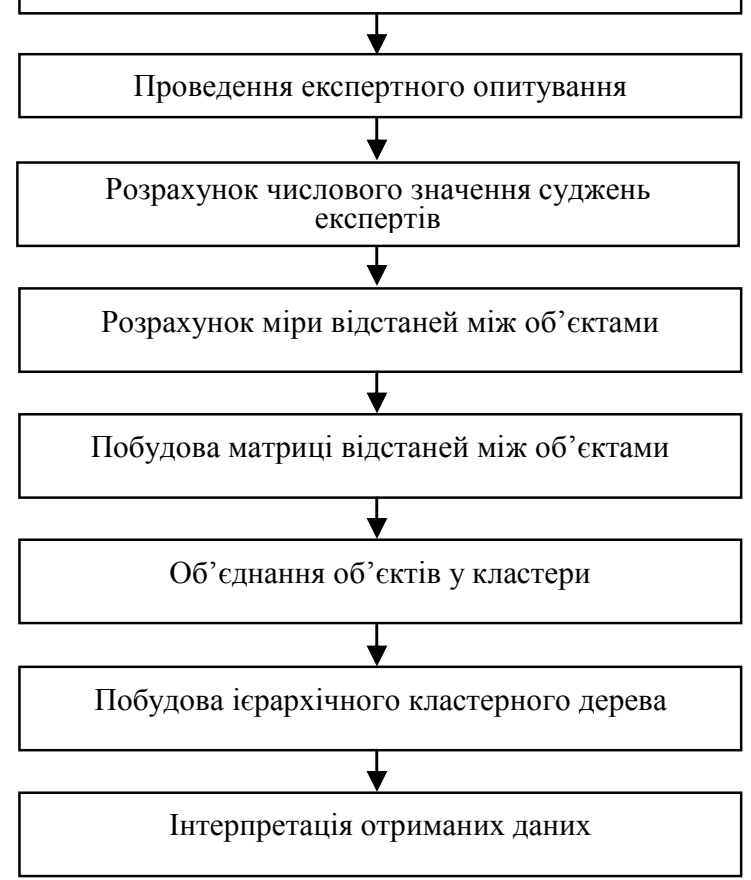

Рисунок 2. Алгоритм методики визначення структури ОУР

\section{Висновки й перспективи подальших досліджень}

Запропонована методика визначення раціональної структури ОУР на основі методу кластерного аналізу. Метою кластерного аналізу $є$ пошук наявних структур, що виражається в утворенні груп схожих між собою об'єктів кластерів. На відміну від інших методів, цей метод дає змогу класифікувати об'єкти не за однією, а за декількома ознаками одночасно як сукупність взаємопов'язаних функціональних підсистем 3 визначенням функцій кожної з них.

Викладені результати дослідження обгрунтовані практичними розрахунками і можуть бути застосовані для удосконалення науковометодичного апарату визначення, оцінювання ефективності розроблених варіантів структури ОУР та вибору найбільш прийнятної альтернативи.

Подальші дослідження слід спрямувати на розробці методів оцінювання ефективності ОУР.

2. Потьомкін М. М. Ветодика визначення раціонального складу складної системи військового призначення на основі модифікованого методу ELECTRE [Tекст] / M. М. Потьомкін // Зб. наук. пр. ЦНДІ ЗС України. - К., 2008. - № 3 (45). - С. 62-68. 3. Кластерний аналіз. Загальне поняття, його Modern Information Technologies in the Sphere of Security and Defence № 2(32)/2018 $\quad$ ISSSV2311-7249(Print)/ISSSV2410-7336(Onfine) $\quad 101$ 
математичні основи та завдання. [Електронний ресурс]. - Режим доступу: http:/ib-ko.com/book_346_glava70_\&2.7 k. 4. Методичні вказівки щодо формування структурних підрозділів Міністерства оборони України та визначення їх чисельності. - К.: Міністерство оборони України, 2003. - 11 с. 5. Комаров В.С. Методичний підхід до обгрунтування раціонального складу органів військового управління / В.С.Комаров, О.М.Косогов, В.Ф. Курдюк // Зб. наук. праць. - Х.: Харківський національний університет Повітряних Сил імені Івана Кожедуба №2 (51), 2017, - С. 40-45. 6. Романченко I. C. Використання таксономічних методів при проведенні досліджень у воєнній справі [Текст] / I. С. Романченко, О. М. Загорка // Зб. наук. пр. ЦНДІ ЗС України. - К., 2007. - № 3 (41). - С. 5-16. 7. Елементи дослідження складних систем військового призначення [Текст] / О. М. Загорка, С. П. Мосов, А. І. Сбитнєв, П. І. Стужук. - К.: НАОУ, 2005. - 100 с.

\title{
МЕТОДИКА ОПРЕДЕЛЕНИЯ СТРУКТУРЫ ОРГАНА УПРАВЛЕНИЯ РАЗВЕДКОЙ олексиюк Вадим Виталийович
}

В статье предложена методика обоснования рациональной структуры органов управления разведкой на основе метода кластерного анализа, иелью которого является поиск имеюшихся структур, который выражается $в$ образовании групп похожих между собой объектов - кластеров. Выбор стратегии кластеризации заключается 8 определении правил объединения объектов в кластера. Данные для кластерного анализа готовятся путем формировании матрицы соотношений. В отличие от других методов, этот метод дает возможность классифицировать объекты не за одной, а за несколькими признаками одновременно, как совокупность взаимосвязанных функииональных подсистем с определением функиий каждой из них. Приведен вариант дендограмы объединение кластеров (структурных подразделений) за измерением близости функиий и задач соответственно подсистемам системы. Результаты исследований обоснованы практическими расчетами и могут быть использованы для усовершенствования научно-методического аппарата определения, оценки эффективности разработанных вариантов структур ОУР и выбора наиболее принятной альтернативы.

Ключевые слова: орган управления разведкой, структура, кластерной анализ, Вооруженные Силы Украины.

\section{THE METHOD FOR SUBSTANTIATING THE RATIONAL STRUCTURE OF INTELLIGENCE MANAGEMENT}

\author{
Vadim V. Oleksiuk
}

Military unit A1906 Kyiv, Ukraine

The article proposes a method for substantiating the rational structure of intelligence management on the basis of the cluster analysis method, which goal is to search for available structures, expressed in the formation of groups of similar objects - clusters. The Choice to strategies to clusterizations is concluded in determination of the rules of the association object in кластера. Data for cluster analysis prepare the matrix of the correlations by shaping.

Unlike other methods, this method makes it possible to classify objects not just one, but several attributes at the same time as a set of interrelated functional subsystems with the definition of the functions of each of them. A variant of the dendogram is shown to combine clusters (structural subsections) to measure the proximity of functions and tasks, respectively, to the subsystems of the system. The results of the studies are justified by practical calculations and can be used to improve the scientific and methodological apparatus for determining, evaluating the effectiveness of the developed options for ESD structures and selecting the most acceptable alternative.

Key words: intelligence management, structure, cluster analysis, Armed Forces of Ukraine

\section{References}

1. Kosogov A. M. Methods of the determination of the structure of the system to information safety Ministry of defense Ukraines and Armed Power of the Ukraine / A. M. Kosogov, A. A. Siryk // Zb. nauk. rabot. - H.: Harikovskiy national university of Air Power of the name Ivana Kozheduba 3 (52), 2017, - S. 30-34. 2. Potemkin M. M. Methods of the determination of the rational composition of the complex military system on base of the modified method ELECTRE [Text] / M. M. Potemkin // Zb. nauk. pr. CND_ ZS Ukrainy. - K., 2008. - 3 (45 - S. 62-68. 3. The Cluster analysis. The General notion, his(its) mathematical bases and problems. [Electronic resource - a Mode of the access: http:/ib-ko.com/book_346_glava70_\&-2.7_k. 4. The Methodical instructions for shaping structured subsection
Ministry of defense of the Ukraine and determination their chislennosti. - K.: Ministry of defense of the Ukraine, 2003. 11 s. 5. Komarov V. S. Methodical approach to motivation of the rational composition organ military control / $V$. $S$. Midge, O. M. Kosogov, V. F. Kurdyuk // Zb. nauk. rabot. H.: Harikovskiy national university of Air Power of the name Ivana Kozheduba 2 (51), 2017, - S. 40-45. 6. Romanchenko I. S. Use the taxonomic methods when undertaking the studies in military deal [Text] / I. S. Romanchenko, O. M. Zagorka // Zb. nauk. pr. CND_ZS Ukrainy. - K., 2007. - 3 (41 - S. 5-16. 7. Elements of the study of the complex military systems [Text] / O. M. Zagorka, S. P. Monsieur, A. I. Sbitnev, P. I. Stuzhuk. - K.: NAOU, 2005. - 100 